\title{
An Enhanced SVPWM Strategy Based on Vector Space Decomposition for Dual Three- Phase Machines Fed by Two DC-Source VSIs
}

\author{
Liao, Wu ; Lyu, Mingcheng; Huang, Sheng; Wen, Yuliang ; Li, Mengdi; Huang, Shoudao
}

Published in:

IEEE Transactions on Power Electronics

Link to article, DOI:

10.1109/TPEL.2021.3052913

Publication date:

2021

Document Version

Peer reviewed version

Link back to DTU Orbit

Citation (APA):

Liao, W., Lyu, M., Huang, S., Wen, Y., Li, M., \& Huang, S. (2021). An Enhanced SVPWM Strategy Based on Vector Space Decomposition for Dual Three-Phase Machines Fed by Two DC-Source VSIs. IEEE Transactions on Power Electronics, 36(8), 9312 - 9321. https://doi.org/10.1109/TPEL.2021.3052913

\section{General rights}

Copyright and moral rights for the publications made accessible in the public portal are retained by the authors and/or other copyright owners and it is a condition of accessing publications that users recognise and abide by the legal requirements associated with these rights.

- Users may download and print one copy of any publication from the public portal for the purpose of private study or research.

- You may not further distribute the material or use it for any profit-making activity or commercial gain

- You may freely distribute the URL identifying the publication in the public portal 


\title{
An Enhanced SVPWM Strategy Based on Vector Space Decomposition for Dual Three-Phase Machines Fed by Two DC-Source VSIs
}

\author{
Wu Liao, Mingcheng Lyu, Sheng Huang, Yuliang Wen, Mengdi Li, Shoudao Huang, Senior Member, IEEE
}

\begin{abstract}
This paper presents an enhanced space vector pulse width modulation (SVPWM) strategy based on vector space decomposition (VSD) for the dual three-phase machines fed by two DC-Source voltage source inverters (VSIs). Compared with existing methods that only account for balanced DC-link voltages, the proposed method considers unbalanced DC-link voltages in both the $\alpha-\beta$ and $z_{1}-z_{2}$ planes. Two categories of medium voltage vectors are first defined in this paper. An enhanced 12-sector SVPWM strategy that toggles two categories of medium voltage vectors in each fixed $30^{\circ}$ sector is proposed. Moreover, the performance of the proposed method, including the modulation depth, the range of the DC-link voltage ratio, and the toggling point of the medium vector is analyzed. The proposed method can reduce the computational burden of the complicated sector classifications and it easily chooses suitable vectors to track the reference voltage with changes in the $\mathrm{DC}$-link voltage ratio. The experimental results of the proposed SVPWM techniques are verified in a dual three-phase permanent magnet synchronous machine (PMSM) fed by two DC-Source VSIs.
\end{abstract}

Index Terms-Dual Three-phase Machines, SVPWM, Two DCSource VSIs, Vector Space Decomposition

\section{INTRODUCTION}

$\mathrm{D}$ UAL three-phase machines [1-3] with two sets of threephase windings that are spatially shifted by an electrical angle of $30^{\circ}$ exhibit outstanding advantages, such as fewer torque ripples than other machines, reduced phase current ratings, and excellent fault tolerance. They have much potential for applications in wind power, electric vehicles, electric ship propulsion systems, and electric railway traction [4-5].

The vector space decomposition (VSD) approach [6] can be used to decouple the dual three-phase machine state variables into three two-dimensional orthogonal subplanes $\left(\boldsymbol{\alpha}-\boldsymbol{\beta}, \mathbf{z}_{1}-\mathbf{z}_{2}, \mathbf{o}_{1}\right.$ $\left.\mathbf{0}_{2}\right)$, making it a classical and powerful tool for the analysis and control of dual three-phase machines [7]. Reference [8] showed

Manuscript received September 11, 2020; revised December 2, 2020; accepted January 15,2021. This work was supported by National Natural Science Foundation of China (51737004). (Corresponding author: Sheng Huang. e-mail: huang98123@163.com)

Wu Liao, Mingcheng Lyu, Mengdi Li and Shoudao Huang are with the College of Electrical and Information Engineering, Hunan University, Changsha 410082, China (e-mail: liaowu1988@hnu.edu.cn; 289763620@qq.com; hnuguanging@163.com; hsd1962@hnu.edu.cn).

Sheng Huang is with the Department of Electrical Engineering, Technical University of Denmark, 2800 Kgs. Lyngby. Denmark (e-mail: huang98123@163.com).

Yuliang Wen is with the School of Information Science and Engineering, Central South University, Changsha 410012, China (e-mail: wenyl@csrzic.com). that the current loop control method based on VSD is flexible for controlling the fifth and seventh current harmonics, and it has advantages in terms of stability and robustness. Space vector pulse width modulation (SVPWM) based on the VSD approach can be used to directly suppress the harmonics of a dual three-phase machine, and this subtype is considered a classical SVPWM approach [9]. Many SVPWM techniques based on the VSD method have been investigated for dual three-phase machines [6,9-13], and these can be divided into the 12-sector SVPWM and 24-sector SVPWM methods. 12sector SVPWM adopts four large voltage vectors in the $\boldsymbol{\alpha}-\boldsymbol{\beta}$ plane to synthesize the reference voltage vectors [6]. The 24sector SVPWM methods take advantage of the medium voltage vectors to divide the sectors. Types of this approach include the $(\mathbf{3 L}+\mathbf{1 M})$ method [10], the (2L+1M+1ML) method [11], and the $(\mathbf{3 L}+\mathbf{2 M})$ method [12], where $\mathbf{L}$ stands for the large voltage vectors, ML stands for the medium-large voltage vectors, medium voltage vectors are denoted by $\mathbf{M}$, and small voltage vectors are denoted by $\mathbf{S}$. Compared to the 12 -sector method, the 24-sector method involves fewer switching operations in each PWM cycle, and it is easier to implement in the digital signal processor (DSP). Reference [13] proposed new SVPWM techniques by modifying the switching sequences of carrierbased PWM techniques. The modified SVPWM approach significantly reduces harmonic distortion factor (HDF) and provides low current total harmonic distortion (THD).

Currently, the most studied SVPWM approach for dual three-phase machines is a parallel-connected DC-link system, in which two three-phase two-level VSI DC links are connected in parallel. In fact, dual three-phase machines have different DC-link topologies. In general, DC-link topologies can be divided into three types: parallel-connected [14-16], seriesconnected [17-18], and separated DC-links [19-22], as illustrated in Fig. 1. The parallel-connected system in Fig. 1(a) is the most widely studied. In this case, the DC-link between the two three-phase VSIs has a balanced voltage. The seriesconnected system is shown in Fig. 1(b) and uses two threephase two-level VSIs connected in series to form a cascaded DC-link. The series-connected topology can achieve a double DC-link voltage of three-phase VSIs, however, it follows that any asymmetry will cause DC-link voltage drifting unless some voltage balancing mechanism is included in the control scheme [17]. In fact, asymmetry in a dual three-phase driver system is inevitable because of the asymmetry between any two sets of windings and power inverters [23-24]. Separated DC-links can increase the availability of the drive in case of a failure. Two 


\section{IEEE POWER ELECTRONICS REGULAR PAPER/LETTER/CORRESPONDENCE}

batteries that supply two DC-links of a dual three-phase PMSM are introduced in [19]. If batteries with different nominal voltages are used or the states of charge of the batteries are different, it is not guaranteed that both DC-link voltage levels are always the same [19]. Furthermore, the separated DC-links can provide the system with the ability to integrate different sources of energy [20-22]. A dual three-phase PMSM drive with a battery DC-link and ultracapacitor (or fuel cell) DC-link is investigated in [20-22]. Separated DC-links may also result in an unbalanced DC-link voltage due to the different transferred powers from the battery and ultracapacitor (or fuel cell).

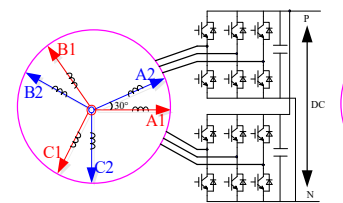

(a)

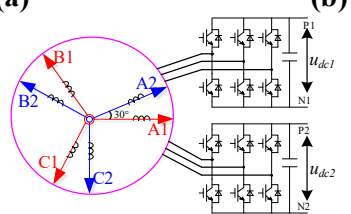

(c)

Fig. 1 DC-links of the dual three-phase machine. (a) Parallel-connected DClinks (b) Series-connected DC-links (c) Separated DC-links

The projections of the voltage vectors in the $\boldsymbol{\alpha}-\boldsymbol{\beta}$ and $\mathbf{z}_{1}-\mathbf{z}_{2}$ planes are directly related to the DC-link voltage. Therefore, the projections of voltage vectors under an unbalanced DC-link voltage are quite different from those under balanced projections. Furthermore, this leads to new modulation issues for conventional VSD-based SVPWM methods. The first issue is that DC-link voltage imbalances cause a non-uniform distribution of the voltage vectors in the $\boldsymbol{\alpha}-\boldsymbol{\beta}$ and $\mathbf{z}_{1}-\mathbf{z}_{2}$ planes, thereby increasing the burden of sector classification and judgment. The second issue is that the selection of vector applications is difficult, as the vector distribution varies with the DC-link voltage ratio. Dual three-phase SVPWM is used to avoid VSD problems under unbalanced DC-link voltages [25], but dual three-phase SVPWM cannot reflect the relationship between stator flux linkage and stator voltage because of the electromagnetic couplings in the two windings. In addition, the synchrony between the dual three-phase windings is need to reduce the sub-harmonics [26]. To the best of the authors' knowledge, there are few studies on VSD-based SVPWM that take unbalanced DC-link voltage into consideration.

In this paper, an SVPWM strategy considering unbalanced DC-link voltages is studied. Two categories of medium voltage vectors are first defined in this paper. An enhanced 12-sector SVPWM strategy is proposed that toggles two categories of medium voltage vectors in the $\boldsymbol{\alpha}-\boldsymbol{\beta}$ plane with a fixed $30^{\circ}$ sector. The proposed method avoids complicated sector classification and judgment algorithms under non-uniform voltage vector distributions, and easily chooses the correct vector (positive application time) to track the reference voltage with changes in DC-link voltage ratio. Moreover, the performance of the proposed method, i.e., the modulation depth, the range of the DC-link voltage ratio, and the toggling point of the medium vector, are analyzed in detail. The effectiveness of the proposed method is verified by the dual three-phase PMSM.

\section{VOLTAGE VECTOR ANALYSES}

The relationship between the dual three-phase motor stator voltage and switch states of the VSI can be presented as:

$$
\begin{aligned}
& {\left[\begin{array}{l}
u_{A 1} \\
u_{B 1} \\
u_{C 1}
\end{array}\right]=u_{d c 1}\left[\begin{array}{ccc}
\frac{2}{3} & -\frac{1}{3} & -\frac{1}{3} \\
-\frac{1}{3} & \frac{2}{3} & -\frac{1}{3} \\
-\frac{1}{3} & -\frac{1}{3} & \frac{2}{3}
\end{array}\right]\left[\begin{array}{l}
S_{A 1} \\
S_{B 1} \\
S_{C 1}
\end{array}\right]} \\
& {\left[\begin{array}{l}
u_{A 2} \\
u_{B 2} \\
u_{C 2}
\end{array}\right]=u_{d c 2}\left[\begin{array}{ccc}
\frac{2}{3} & -\frac{1}{3} & -\frac{1}{3} \\
-\frac{1}{3} & \frac{2}{3} & -\frac{1}{3} \\
-\frac{1}{3} & -\frac{1}{3} & \frac{2}{3}
\end{array}\right]\left[\begin{array}{l}
S_{A 2} \\
S_{B 2} \\
S_{C 2}
\end{array}\right]}
\end{aligned}
$$

where $u_{d c 1}$ and $u_{d c 2}$ represent the voltages of the two DC-links; $u_{\mathrm{A} 1}, u_{\mathrm{B} 1}, u_{\mathrm{C} 1}, u_{\mathrm{A} 2}, u_{\mathrm{B} 2}$ and $u_{\mathrm{C} 2}$ represent the stator phase voltages; and $S_{\mathrm{A} 1}, S_{\mathrm{B} 1}, S_{\mathrm{C} 1}, S_{\mathrm{A} 2}, S_{\mathrm{B} 2}$ and $S_{\mathrm{C} 2}$ represent the upper switch states of the inverters (i.e., "1": ON and "0": OFF). By applying the VSD transformation matrix in (3), the voltage vectors $\mathrm{V}=\mathrm{S}_{\mathrm{A} 1} * 2^{5}+\mathrm{S}_{\mathrm{B} 1} * 2^{4}+\mathrm{S}_{\mathrm{C} 1} * 2^{3}+\mathrm{S}_{\mathrm{A} 2} * 2^{2}+\mathrm{S}_{\mathrm{B} 2} * 2^{1}+\mathrm{S}_{\mathrm{C} 2} * 2^{0}$ can be projected into three orthogonal planes, which are identified as $\boldsymbol{\alpha}-\boldsymbol{\beta}, \mathbf{z}_{1}-\mathbf{Z}_{2}$, and $\mathbf{0}_{1}-\mathbf{o}_{2}$, respectively. The third subplane $\mathbf{0}_{1}-\mathbf{o}_{\mathbf{2}}$ is excluded due to isolated neutral point.

$$
\left[\begin{array}{l}
u_{\alpha} \\
u_{\beta} \\
u_{\mathrm{z} 1} \\
u_{z 2} \\
u_{o 1} \\
u_{o 2}
\end{array}\right]=\sqrt{\frac{1}{3}}\left[\begin{array}{cccccc}
1 & -\frac{1}{2} & -\frac{1}{2} & \frac{\sqrt{3}}{2} & -\frac{\sqrt{3}}{2} & 0 \\
0 & \frac{\sqrt{3}}{2} & -\frac{\sqrt{3}}{2} & \frac{1}{2} & \frac{1}{2} & -1 \\
1 & -\frac{1}{2} & -\frac{1}{2} & -\frac{\sqrt{3}}{2} & \frac{\sqrt{3}}{2} & 0 \\
0 & -\frac{\sqrt{3}}{2} & \frac{\sqrt{3}}{2} & \frac{1}{2} & \frac{1}{2} & -1 \\
1 & 1 & 1 & 0 & 0 & 0 \\
0 & 0 & 0 & 1 & 1 & 1
\end{array}\right]\left[\begin{array}{l}
u_{A 1} \\
u_{B 1} \\
u_{C 1} \\
u_{A 2} \\
u_{B 2} \\
u_{C 2}
\end{array}\right]
$$

The voltage vector projections into the $\boldsymbol{\alpha}-\boldsymbol{\beta}$ and $\mathbf{z}_{1}-\mathbf{z}_{2}$ planes are directly related to the two DC-link voltages. Therefore, it is necessary to further analyze the voltage vector projections under two DC-link voltages.

(1) Large Vectors (i.e., vectors 36 and 37). As an example, the projection coordinates of vector 36 in the $\boldsymbol{\alpha}-\boldsymbol{\beta}$ and $\mathbf{z}_{1}-\mathbf{z}_{2}$ planes are $\left(\frac{1}{\sqrt{3}} u_{d c 1}+\frac{1}{2} u_{d c 2}, \frac{1}{2 \sqrt{3}} u_{d c 2}\right)$ and $\left(\frac{1}{\sqrt{3}} u_{d c 1}\right.$ $\left.\frac{1}{2} u_{d c 2}, \frac{1}{2 \sqrt{3}} u_{d c 2}\right)$, respectively. An illustration of how the symmetric vectors 36 and $\mathbf{3 7}$ change with the unbalanced DClink voltage is shown in Fig. 2(a). It can be seen that both the magnitude and phase of the large vector change with the variation in the DC-link voltage ratio. The angle between vectors 36 and 37 in the $\boldsymbol{\alpha}-\boldsymbol{\beta}$ plane changes from $30^{\circ}$ to $60^{\circ}$ when $\mathrm{k} \rightarrow 0$ and to $0^{\circ}$ when $\mathrm{k} \rightarrow \infty$. $\mathrm{k}$ is the DC-link voltage ratio which can be defined as

$$
\left\{\begin{array}{l}
k=\frac{u_{d c 1}}{u_{d c 2}} \\
\max \left(u_{d c 1}, u_{d c 2}\right)=u_{d c}
\end{array}\right.
$$

where $u_{d c}$ is the nominal DC-link voltage.

(2) Medium Vectors (i.e., 39 and 4). The coordinates of vector 39 in the $\boldsymbol{\alpha}-\boldsymbol{\beta}$ and $\mathbf{z}_{1}-\mathbf{z}_{2}$ planes are $\left(\frac{u_{d c}}{\sqrt{3}}, 0\right)$ and $\left(\frac{u_{d c 1}}{\sqrt{3}}, 0\right)$, and those of vector 4 are $\left(\frac{u_{d c 2}}{2}, \frac{u_{d c}}{2 \sqrt{3}}\right)$ and $\left(-\frac{u_{d c 2}}{2}, \frac{u_{d c 2}}{2 \sqrt{3}}\right)$, 


\section{IEEE POWER ELECTRONICS REGULAR PAPER/LETTER/CORRESPONDENCE}

respectively, From Fig.2(b), it can be seen that the phase of the medium vector is held constant even though the DC voltage ratio changes. The magnitude of vector 4 remains constant when $\mathrm{k}$ changes from 1 to 0 , while the magnitude of vector 39 becomes zero.

(3) Medium-Large Vectors (i.e., 53 and 44) and Small Vectors (i.e., 46 and 49). The distribution patterns of these vectors can be obtained by using the same principle, and they are illustrated in Fig. 2(c) and 2(d).

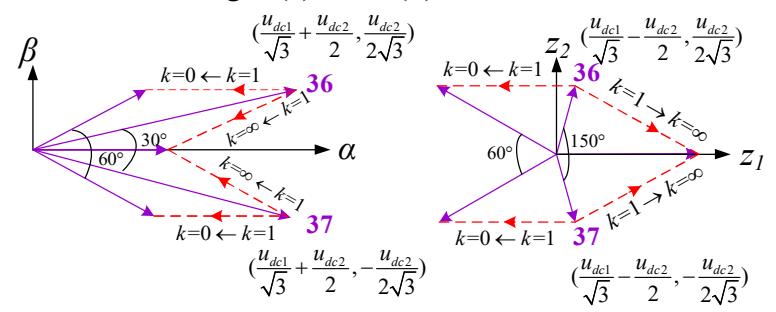

(a)
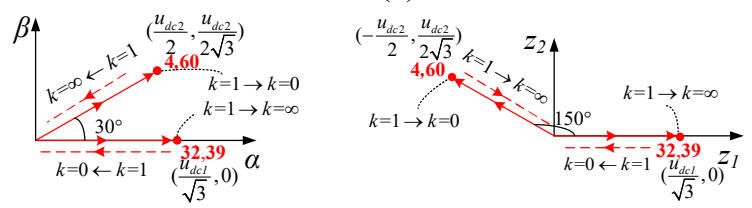

(b)

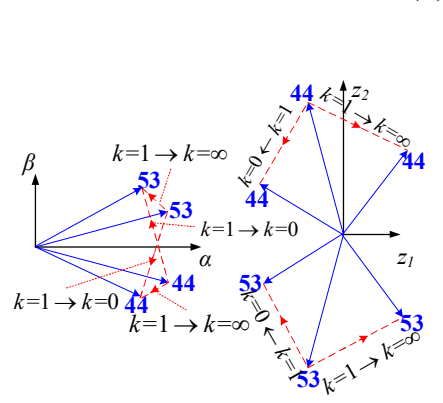

(c)

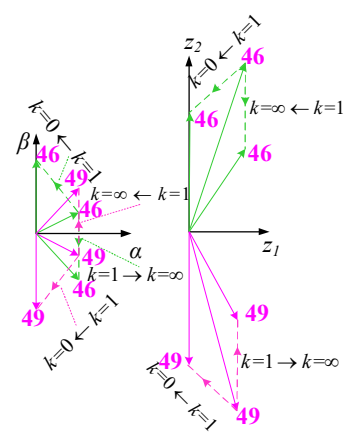

(d)
Fig. 2 Four types of vector distributions with DC-link voltage changes. (a) Large vector variation (b) Medium vector variation (c) Medium-large vector variation (d) Small vector variation

The projections of the 64 voltage vectors (except zero vectors) into the $\boldsymbol{\alpha}-\boldsymbol{\beta}$ and $\mathbf{z}_{\mathbf{1}}-\mathbf{z}_{\mathbf{2}}$ planes with an unbalanced DC-link voltage $(k<1, k=1, k>1)$ are shown in Fig. 3. The above analysis shows that the magnitudes and phases of the large vectors, medium-large vectors and small vectors change when the DClink voltage ratio varies. Therefore, the borders of each sector vary with the unbalanced DC-link voltage. The conventional VSD-based SVPWM methods may no longer be suitable for series-connected or separated DC link-based VSI. This paper proposes an SVPWM method for toggling the medium vector with fixed $30^{\circ}$ sector angle to improve the control performance of the two DC-source VSIs fed dual three-phase machine.

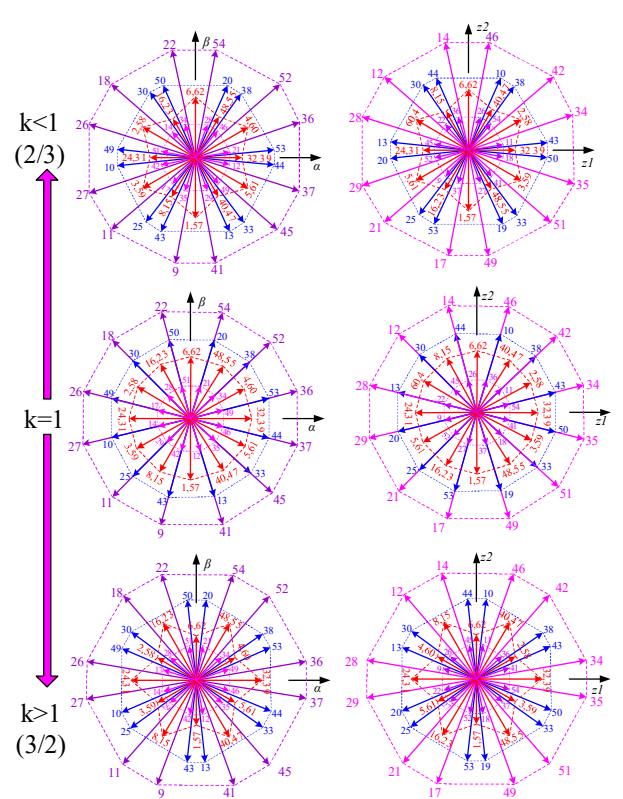

Fig. 3 Projections of phase voltage space vectors in the $\boldsymbol{\alpha}-\boldsymbol{\beta}$ and $\mathbf{z}_{\mathbf{1}}-\mathbf{z}_{\mathbf{2}}$ planes considering an unbalanced DC-link voltage.

\section{PROPOSED SVPWM ALGORITHM}

\section{A. 12-Sector Division}

Based on the analysis in Section II, the phases of all vectors except the medium voltage vectors vary with the DC-link voltage ratio, leading to a non-uniform vector distribution in the $\boldsymbol{\alpha}-\boldsymbol{\beta}$ and $\mathbf{z}_{1}-\mathbf{z}_{2}$ planes. To reduce the complexity of sector selection, the proposed SVPWM method chooses the medium vectors as the borders of each sector. Hence, only 12 sectors with fixed $30^{\circ}$ angles are required in the $\boldsymbol{\alpha}-\boldsymbol{\beta}$ plane, thereby optimizing the sector selection process under DC-link voltage imbalances.

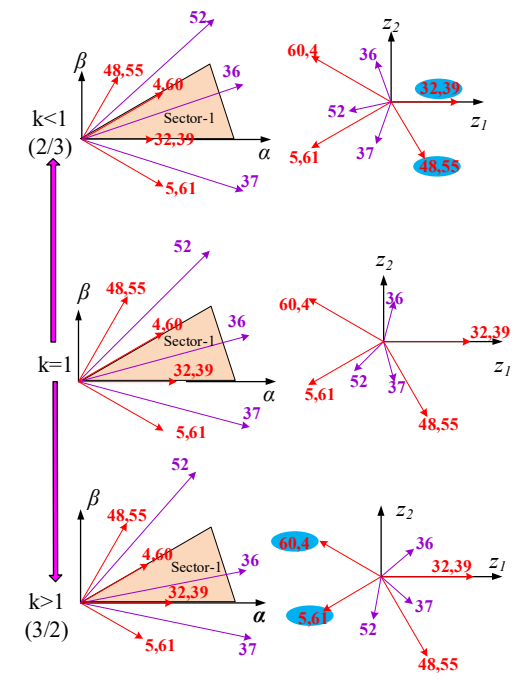

Fig. 4 Presentation of the large and medium vectors at different DC-link voltage ratios.

B. Definition of the Two Categories of Medium Vectors

During each PWM cycle, a set of four nonzero voltage vectors must be chosen to synthesize the reference voltage vectors in VSD-based SVPWM. Since the large vectors in the $\boldsymbol{\alpha}-\boldsymbol{\beta}$ plane have the smallest magnitudes in the $\mathbf{z}_{1}-\mathbf{z}_{2}$ plane, this 


\section{IEEE POWER ELECTRONICS REGULAR PAPER/LETTER/CORRESPONDENCE}

paper chooses three large vectors to increase the modulation ratio in the $\boldsymbol{\alpha}-\boldsymbol{\beta}$ plane. For example, when a reference voltage vector of the $\boldsymbol{\alpha}-\boldsymbol{\beta}$ plane is located in sector-1, large vector 36 is always in this sector even though the DC-link voltage ratio changes. Vectors $\mathbf{5 2}$ and $\mathbf{3 7}$ can also be chosen because they are adjacent to 36. As indicated by Fig. 4, large vectors 36,37 and 52 in the $\mathbf{z}_{1}-\mathbf{z}_{2}$ plane converge towards the half-plane as the DClink voltage imbalance increases. In other words, it is necessary to use other voltage vectors to make the average volt-second on this plane be zeroed. Therefore, this paper selects the medium vectors whose phases remain constant to compensate for the volt-second produced by large vectors in the $\mathbf{z}_{1}-\mathbf{z}_{2}$ plane. In fact, one or multiple medium vectors with fixed time proportions could be selected. To simplify the calculations, an equal time distribution is adopted when two medium voltage vectors are selected, as this reduces the amplitude fluctuations of the stator flux caused by the long-time operation of one vector [25]. As shown in Fig. 4, the possible medium voltage vectors are 32, 39 and 48,55 when $\mathrm{k}<1$, and these are highlighted in light blue. In contrast, the possible medium vectors change to 60,4 and 5,61 when $\mathrm{k}>1$.

If the validity of time is not considered first, the application times in sector-1 with medium vectors $\left(\mathbf{3 9}, \mathbf{6 0}, 39_{\text {and }} \mathbf{4 8 , 6 0 _ { \text { and } } 5 )}\right.$ can be calculated by:

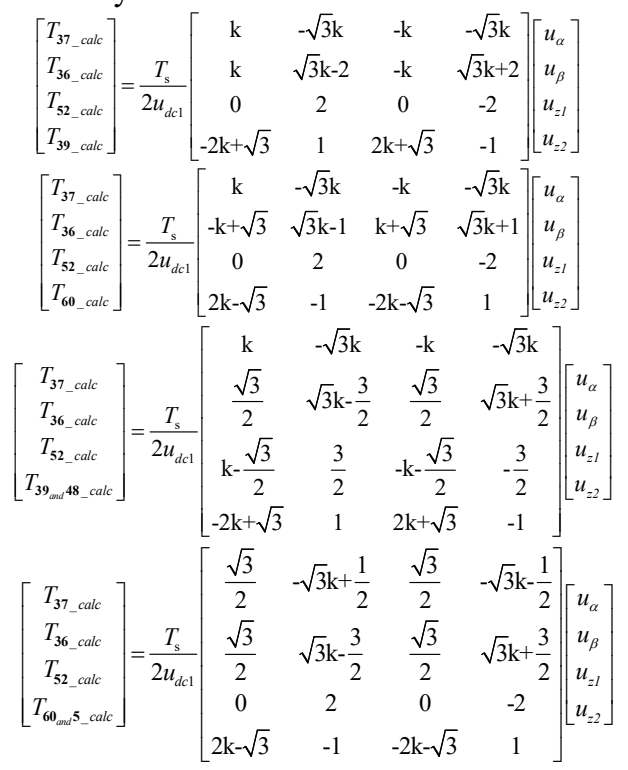

where $\mathrm{T}$ represents the calculated vector application time and subscripts indicate the vectors involved. $\mathrm{T}_{\mathrm{s}}$ represents the PWM period, and $u_{\alpha}, u_{\beta}, u_{\mathrm{z} 1}$, and $u_{\mathrm{z} 2}$ represent the reference voltages. It should be noted that the calculated application times of the four categories medium voltage vectors have equal absolute values. The interesting relationships among the application times of the medium vectors are indicated in (9):

$$
\left\{\begin{array}{l}
T_{39_{\text {_calc }}}=T_{39_{\text {and }} \mathbf{4 8} \_ \text {calc }} \\
T_{60 \_c a l c}=T_{60} \mathbf{0}_{\text {and }} 5_{\text {_calc }} \\
T_{39 \_c a l c}=-T_{60 \_c a l c}
\end{array}\right.
$$

Based on the application times of the medium vectors, this paper classifies the medium vectors 39,39 and 48 as type-1 medium vectors in sector- 1 , while vectors $6 \mathbf{0 0}, \mathbf{6 0}$ and $\mathbf{5}$ are classified as type-2 medium vectors. The classifications of the medium vectors in the whole sector are shown in Table I. TABLE I

\begin{tabular}{|c|c|c|}
\hline Sector & Type-1 medium vectors & Type-2 medium vectors \\
\hline 1 & $39,32,39_{\text {and }} 48,32$ and 55 & $4,60,5_{\text {and }} 60,4_{\text {and }} 61$ \\
\hline 2 & $48,55,39$ and 48,32 and 55 & $4,60,6_{\text {and }} 60,4$ and 62 \\
\hline 3 & $48,55,23_{\text {and }} 48,16$ and 55 & $6,62,6_{\text {and }} 60,4_{\text {and }} 62$ \\
\hline 4 & $16,23,23_{\text {and }} 48,16$ and 55 & $6,62,6_{\text {and }} 58,2_{\text {and }} 62$ \\
\hline 5 & $16,23,16$ and 31,23 and 24 & $2,58,6_{\text {and }} 58,2$ and 62 \\
\hline 6 & $24,31,16$ and 31,23 and 24 & $2,58,3_{\text {and }} 58,2$ and 59 \\
\hline 7 & $24,31,8_{\text {and }} 31,15_{\text {and }} 24$ & $3,59,3_{\text {and }} 58,2$ and 59 \\
\hline 8 & $8,15,8_{\text {and }} 31,15_{\text {and }} 24$ & $3,59,3_{\text {and }} 57,1_{\text {and }} 59$ \\
\hline 9 & $8,15,8_{\text {and }} 47,15$ and 40 & $1,57,3_{\text {and }} 57,1_{\text {and }} 59$ \\
\hline 10 & $40,47,8$ and 47,15 and 40 & $1,57,5_{\text {and }} 57,1_{\text {and }} 61$ \\
\hline 11 & $40,47,32_{\text {and }} 47,39$ and 40 & $5,61,5_{\text {and }} 57,1_{\text {and }} 61$ \\
\hline 12 & $39,32,32$ and 47,39 and 40 & $5,61,5_{\text {and }} 60,4_{\text {and }} 61$ \\
\hline
\end{tabular}

CLASSIFICATIONS OF MEDIUM VECTORS

C. Proposed SVPWM for Toggling the Medium Voltage Vectors

Because the type- 1 and type- 2 medium vectors have the opposite calculated application times, it is possible to toggle two types of medium vectors if the calculated application time of medium vector is less than zero. This paper defines the proposed medium vector toggling method with only one medium vector in a PWM period as C6ФSVPWM12-A, and with two medium vectors as C6ФSVPWM12-B. The vector sequences and application times are shown in Table II, where $T_{n}(n=1 \ldots 30)$ represents the nonzero vector application times, as shown in Appendix A. $T_{0}$ is the remaining times which the zero vectors $(\mathbf{0}, \mathbf{7}, \mathbf{5 6}$ or $\mathbf{6 3})$ are applied.

\begin{tabular}{|c|c|c|}
\hline Sector & Vector sequences & Vector applying times \\
\hline \multirow{2}{*}{1} & $7,37,36,52,60,56$ & $\mathrm{~T}_{0} / 2, \mathrm{~T}_{1}, \mathrm{~T}_{2}, \mathrm{~T}_{3}, \mathrm{~T}_{4}, \mathrm{~T}_{0} / 2$ \\
\hline & $7,39,37,36,52,56$ & $\mathrm{~T}_{0} / 2,-\mathrm{T}_{4}, \mathrm{~T}_{1}, \mathrm{~T}_{9}, \mathrm{~T}_{3}, \mathrm{~T}_{0} / 2$ \\
\hline \multirow{2}{*}{2} & $63,54,52,36,4,0$ & $\mathrm{~T}_{0} / 2,-\mathrm{T}_{1}, \mathrm{~T}_{6}, \mathrm{~T}_{5}, \mathrm{~T}_{7}, \mathrm{~T}_{0} / 2$ \\
\hline & $63,55,54,52,36,0$ & $\mathrm{~T}_{0} / 2,-\mathrm{T}_{7},-\mathrm{T}_{1}, \mathrm{~T}_{11}, \mathrm{~T}_{5}, \mathrm{~T}_{0} / 2$ \\
\hline \multirow{2}{*}{3} & $56,52,54,22,6,7$ & $\mathrm{~T}_{0} / 2, \mathrm{~T}_{8},-\mathrm{T}_{4},-\mathrm{T}_{5}, \mathrm{~T}_{9}, \mathrm{~T}_{0} / 2$ \\
\hline & $56,48,52,54,22,7$ & $\mathrm{~T}_{0} / 2,-\mathrm{T}_{9}, \mathrm{~T}_{8}, \mathrm{~T}_{2},-\mathrm{T}_{5}, \mathrm{~T}_{0} / 2$ \\
\hline \multirow{2}{*}{4} & $0,18,22,54,62,63$ & $\mathrm{~T}_{0} / 2,-\mathrm{T}_{8}, \mathrm{~T}_{11}, \mathrm{~T}_{10},-\mathrm{T}_{6}, \mathrm{~T}_{0} / 2$ \\
\hline & $0,16,18,22,54,63$ & $\mathrm{~T}_{0} / 2, \mathrm{~T}_{6},-\mathrm{T}_{8}, \mathrm{~T}_{7}, \mathrm{~T}_{10}, \mathrm{~T}_{0} / 2$ \\
\hline \multirow{2}{*}{5} & $7,22,18,26,58,56$ & $\mathrm{~T}_{0} / 2, \mathrm{~T}_{12},-\mathrm{T}_{9},-\mathrm{T}_{10}, \mathrm{~T}_{2}, \mathrm{~T}_{0} / 2$ \\
\hline & $7,23,22,18,26,56$ & $\mathrm{~T}_{0} / 2,-\mathrm{T}_{2}, \mathrm{~T}_{12},-\mathrm{T}_{3},-\mathrm{T}_{10}, \mathrm{~T}_{0} / 2$ \\
\hline 6 & $\begin{array}{c}63,27,26,18,2,0 \\
63,31,27,26,18,0\end{array}$ & $\begin{array}{l}\mathrm{T}_{0} / 2,-\mathrm{T}_{12}, \mathrm{~T}_{7}, \mathrm{~T}_{3},-\mathrm{T}_{11}, \mathrm{~T}_{0} / 2 \\
\mathrm{~T}_{0} / 2, \mathrm{~T}_{11},-\mathrm{T}_{12},-\mathrm{T}_{6}, \mathrm{~T}_{3}, \mathrm{~T}_{0} / 2\end{array}$ \\
\hline \multirow{2}{*}{7} & $56,26,27,11,3,7$ & $\mathrm{~T}_{0} / 2,-\mathrm{T}_{1},-\mathrm{T}_{2},-\mathrm{T}_{3},-\mathrm{T}_{4}, \mathrm{~T}_{0} / 2$ \\
\hline & $56,24,26,27,11,7$ & $\mathrm{~T}_{0} / 2, \mathrm{~T}_{4},-\mathrm{T}_{1},-\mathrm{T}_{9},-\mathrm{T}_{3}, \mathrm{~T}_{0} / 2$ \\
\hline \multirow{2}{*}{8} & $0,9,11,27,59,63$ & $\mathrm{~T}_{0} / 2, \mathrm{~T}_{1},-\mathrm{T}_{6},-\mathrm{T}_{5},-\mathrm{T}_{7}, \mathrm{~T}_{0} / 2$ \\
\hline & $0,8,9,11,27,63$ & $\mathrm{~T}_{0} / 2, \mathrm{~T}_{7}, \mathrm{~T}_{1},-\mathrm{T}_{11},-\mathrm{T}_{5}, \mathrm{~T}_{0} / 2$ \\
\hline \multirow{2}{*}{9} & $\mathbf{7 , 1 1 , 9 , 4 1 , 5 7 , 5 6}$ & $\mathrm{T}_{0} / 2,-\mathrm{T}_{8}, \mathrm{~T}_{3}, \mathrm{~T}_{5},-\mathrm{T}_{9}, \mathrm{~T}_{0} / 2$ \\
\hline & $7,15,11,9,41,56$ & $\mathrm{~T}_{0} / 2, \mathrm{~T}_{9},-\mathrm{T}_{8},-\mathrm{T}_{2}, \mathrm{~T}_{5}, \mathrm{~T}_{0} / 2$ \\
\hline \multirow{2}{*}{10} & $63,45,41,9,1,0$ & $\mathrm{~T}_{0} / 2, \mathrm{~T}_{8},-\mathrm{T}_{11},-\mathrm{T}_{10}, \mathrm{~T}_{6}, \mathrm{~T}_{0} / 2$ \\
\hline & $63,47,45,41,9,0$ & $\mathrm{~T}_{0} / 2,-\mathrm{T}_{6}, \mathrm{~T}_{8},-\mathrm{T}_{7},-\mathrm{T}_{10}, \mathrm{~T}_{0} / 2$ \\
\hline \multirow{2}{*}{11} & $56,41,45,37,5,7$ & $\mathrm{~T}_{0} / 2,-\mathrm{T}_{12}, \mathrm{~T}_{9}, \mathrm{~T}_{10},-\mathrm{T}_{2}, \mathrm{~T}_{0} / 2$ \\
\hline & $56,40,41,45,37,7$ & $\mathrm{~T}_{0} / 2, \mathrm{~T}_{2},-\mathrm{T}_{12}, \mathrm{~T}_{3}, \mathrm{~T}_{10}, \mathrm{~T}_{0} / 2$ \\
\hline \multirow{2}{*}{12} & $0,36,37,45,61,63$ & $\mathrm{~T}_{0} / 2, \mathrm{~T}_{12},-\mathrm{T}_{7},-\mathrm{T}_{3}, \mathrm{~T}_{11}, \mathrm{~T}_{0} / 2$ \\
\hline & $0,32,36,37,45,63$ & $\mathrm{~T}_{0} / 2,-\mathrm{T}_{11}, \mathrm{~T}_{12}, \mathrm{~T}_{6},-\mathrm{T}_{3}, \mathrm{~T}_{0} / 2$ \\
\hline
\end{tabular}
TABLE II

The voltage vector application sequences in sector-1 with medium vectors $\left(39,60,39_{\text {and }} \mathbf{4 8}, \mathbf{6 0}_{\text {and }} 5\right)$ are illustrated in Fig. 5. It can be observed that there are only two switching actions in each phase. Hence, the switching frequencies can be regarded as equivalent. According to the above analysis, the 12 -sector medium vector toggling modulation scheme can be obtained, and it is illustrated in Fig. 6. 
TABLE III

\begin{tabular}{|c|c|c|}
\hline Sector & Vector sequences & Vector applying times \\
\hline \multirow{2}{*}{1} & $7,5,37,36,52,60,56$ & $\mathrm{~T}_{0} / 2, \mathrm{~T}_{4} / 2, \mathrm{~T}_{13}, \mathrm{~T}_{14}, \mathrm{~T}_{3}, \mathrm{~T}_{4} / 2, \mathrm{~T}_{0} / 2$ \\
\hline & $7,39,37,36,52,48,56$ & $\mathrm{~T}_{0} / 2,-\mathrm{T}_{4} / 2, \mathrm{~T}_{1}, \mathrm{~T}_{14}, \mathrm{~T}_{17},-\mathrm{T}_{4} / 2, \mathrm{~T}_{0} / 2$ \\
\hline \multirow{2}{*}{2} & $0,32,36,52,54,55,63$ & $\mathrm{~T}_{0} / 2,-\mathrm{T}_{7} / 2, \mathrm{~T}_{18}, \mathrm{~T}_{15},-\mathrm{T}_{1},-\mathrm{T}_{7} / 2, \mathrm{~T}_{0} / 2$ \\
\hline & $0,4,36,52,54,62,63$ & $\mathrm{~T}_{0} / 2, \mathrm{~T}_{7} / 2, \mathrm{~T}_{5}, \mathrm{~T}_{15}, \mathrm{~T}_{16}, \mathrm{~T}_{7} / 2, \mathrm{~T}_{0} / 2$ \\
\hline \multirow{2}{*}{3} & $56,60,52,54,22,6,7$ & $\mathrm{~T}_{0} / 2, \mathrm{~T}_{9} / 2, \mathrm{~T}_{19}, \mathrm{~T}_{20},-\mathrm{T}_{5}, \mathrm{~T}_{9} / 2, \mathrm{~T}_{0} / 2$ \\
\hline & $56,48,52,54,22,23,7$ & $\mathrm{~T}_{0} / 2,-\mathrm{T}_{9} / 2, \mathrm{~T}_{8}, \mathrm{~T}_{20}, \mathrm{~T}_{23},-\mathrm{T}_{9} / 2 \mathrm{~T}_{0} / 2$ \\
\hline \multirow{2}{*}{4} & $63,55,54,22,18,16,0$ & $\mathrm{~T}_{0} / 2, \mathrm{~T}_{6} / 2, \mathrm{~T}_{24}, \mathrm{~T}_{21},-\mathrm{T}_{8}, \mathrm{~T}_{6} / 2, \mathrm{~T}_{0} / 2$ \\
\hline & $63,62,54,22,18,2,0$ & $\mathrm{~T}_{0} / 2,-\mathrm{T}_{6} / 2, \mathrm{~T}_{10}, \mathrm{~T}_{21}, \mathrm{~T}_{22},-\mathrm{T}_{6} / 2, \mathrm{~T}_{0} / 2$ \\
\hline \multirow{2}{*}{5} & $7,6,22,18,26,58,56$ & $\mathrm{~T}_{0} / 2, \mathrm{~T}_{2} / 2, \mathrm{~T}_{25}, \mathrm{~T}_{26},-\mathrm{T}_{10}, \mathrm{~T}_{2} / 2, \mathrm{~T}_{0} / 2$ \\
\hline & $7,23,22,18,26,24,56$ & $\mathrm{~T}_{0} / 2,-\mathrm{T}_{2} / 2, \mathrm{~T}_{12}, \mathrm{~T}_{26}, \mathrm{~T}_{29},-\mathrm{T}_{2} / 2, \mathrm{~T}_{0} / 2$ \\
\hline \multirow{2}{*}{6} & $0,16,18,26,27,31,63$ & $\mathrm{~T}_{0} / 2, \mathrm{~T}_{11} / 2, \mathrm{~T}_{30}, \mathrm{~T}_{27},-\mathrm{T}_{12}, \mathrm{~T}_{11} / 2, \mathrm{~T}_{0} / 2$ \\
\hline & $0,2,18,26,27,59,63$ & $\mathrm{~T}_{0} / 2,-\mathrm{T}_{11} / 2, \mathrm{~T}_{3}, \mathrm{~T}_{27}, \mathrm{~T}_{28},-\mathrm{T}_{11} / 2, \mathrm{~T}_{0} / 2$ \\
\hline \multirow{2}{*}{7} & $56,58,26,27,11,3,7$ & $\mathrm{~T}_{0} / 2,-\mathrm{T}_{4} / 2,-\mathrm{T}_{13},-\mathrm{T}_{14},-\mathrm{T}_{3},-\mathrm{T}_{4} / 2, \mathrm{~T}_{0} / 2$ \\
\hline & $56,24,26,27,11,15,7$ & $\mathrm{~T}_{0} / 2, \mathrm{~T}_{4} / 2,-\mathrm{T}_{1},-\mathrm{T}_{14},-\mathrm{T}_{17}, \mathrm{~T}_{4} / 2, \mathrm{~T}_{0} / 2$ \\
\hline \multirow{2}{*}{8} & $63,31,27,11,9,8,0$ & $\mathrm{~T}_{0} / 2, \mathrm{~T}_{7} / 2,-\mathrm{T}_{18},-\mathrm{T}_{15}, \mathrm{~T}_{1}, \mathrm{~T}_{7} / 2, \mathrm{~T}_{0} / 2$ \\
\hline & $63,59,27,11,9,1,0$ & $\mathrm{~T}_{0} / 2,-\mathrm{T}_{7} / 2,-\mathrm{T}_{5},-\mathrm{T}_{15},-\mathrm{T}_{16},-\mathrm{T}_{7} / 2, \mathrm{~T}_{0} / 2$ \\
\hline 9 & $\begin{array}{c}7,3,11,9,41,57,56 \\
7,15,11,9,41,40,56\end{array}$ & $\begin{array}{c}\mathrm{T}_{0} / 2,-\mathrm{T}_{9} / 2,-\mathrm{T}_{19},-\mathrm{T}_{20}, \mathrm{~T}_{5},-\mathrm{T}_{9} / 2, \mathrm{~T}_{0} / 2 \\
\mathrm{~T}_{0} / 2, \mathrm{~T}_{9} / 2,-\mathrm{T}_{8},-\mathrm{T}_{20},-\mathrm{T}_{23}, \mathrm{~T}_{9} / 2 \mathrm{~T}_{0} / 2\end{array}$ \\
\hline \multirow{2}{*}{10} & $0,8,9,41,45,47,63$ & $\mathrm{~T}_{0} / 2,-\mathrm{T}_{6} / 2,-\mathrm{T}_{24},-\mathrm{T}_{21}, \mathrm{~T}_{8},-\mathrm{T}_{6} / 2, \mathrm{~T}_{0} / 2$ \\
\hline & $0,1,9,41,45,61,63$ & $\mathrm{~T}_{0} / 2, \mathrm{~T}_{6} / 2,-\mathrm{T}_{10},-\mathrm{T}_{21},-\mathrm{T}_{22}, \mathrm{~T}_{6} / 2, \mathrm{~T}_{0} / 2$ \\
\hline \multirow{2}{*}{11} & $56,57,41,45,37,5,7$ & $\mathrm{~T}_{0} / 2,-\mathrm{T}_{2} / 2,-\mathrm{T}_{25},-\mathrm{T}_{26}, \mathrm{~T}_{10},-\mathrm{T}_{2} / 2, \mathrm{~T}_{0} / 2$ \\
\hline & $56,40,41,45,37,39,7$ & $\mathrm{~T}_{0} / 2, \mathrm{~T}_{2} / 2,-\mathrm{T}_{12},-\mathrm{T}_{26},-\mathrm{T}_{29}, \mathrm{~T}_{2} / 2, \mathrm{~T}_{0} / 2$ \\
\hline \multirow{2}{*}{12} & $63,47,45,37,36,32,0$ & $\mathrm{~T}_{0} / 2,-\mathrm{T}_{11} / 2,-\mathrm{T}_{30},-\mathrm{T}_{27}, \mathrm{~T}_{12},-\mathrm{T}_{11} / 2, \mathrm{~T}_{0} / 2$ \\
\hline & $63,61,45,37,36,4,0$ & $\mathrm{~T}_{0} / 2, \mathrm{~T}_{11} / 2,-\mathrm{T}_{3},-\mathrm{T}_{27},-\mathrm{T}_{28}, \mathrm{~T}_{11} / 2, \mathrm{~T}_{0} / 2$ \\
\hline
\end{tabular}

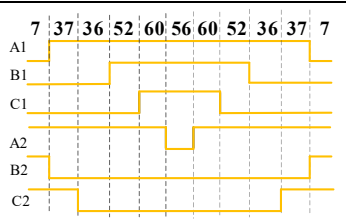

(a)

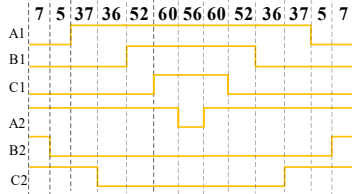

(c)

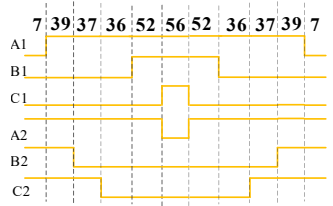

(b)

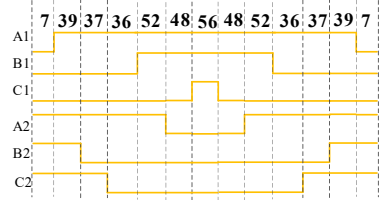

(d)
Fig. 5 The voltage vector application sequences in sector-1. (a) Sequences for vectors 37, 36, 52, 60 (b) Sequences for vectors 37, 36, 52, 39 (c) Sequences for vectors $37,36,52,60$ and 5 (d) Sequences for vectors $37,36,52,39$ and 48

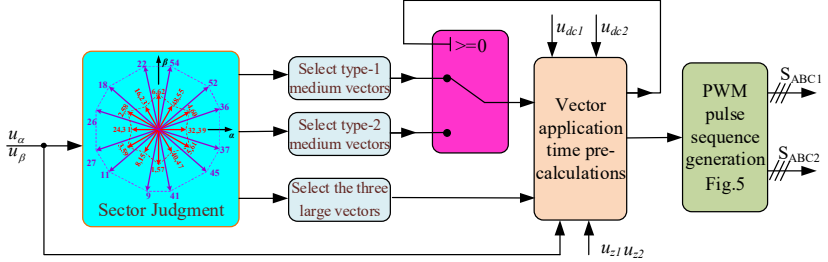

Fig. 6 Flowchart of 12 -sector medium vector toggling modulation

D. Analysis of the medium vector toggling modulation method

This section analyzes the proposed modulation method in terms of three aspects: the range of the DC-link voltage ratio, modulation depth, and toggling points of two types of medium vectors.

(1) Effective range of the DC-link voltage ratio

There are two factors affecting the application times of the vectors: the DC-link voltages $u_{d c l}$ and $u_{d c 2}$, and the reference voltage. The magnitude and phase of the reference voltage in the $\boldsymbol{\alpha}-\boldsymbol{\beta}$ plane are denoted by $u_{\text {ref }}$ and $\theta$, respectively, and $\theta$ is $0<\theta<30^{\circ}$ in sector- 1 . Since the voltage reference in the $\mathbf{z}_{1}-\mathbf{z}_{2}$ plane is much lower than that in the $\boldsymbol{\alpha}-\boldsymbol{\beta}$ plane [13], it can be assumed to be zero during the analysis. Based on the monotonicity of the large vector's application times, the large vectors with the shortest application times in (5)-(8) can be derived and illustrated in (10)-(13).

$$
\begin{aligned}
& \min \left(T_{36_{-} c a l c}\right)=\frac{\sqrt{3} T_{s} u_{r e f}}{4 u_{d c 2}}+\frac{T_{s}\left(\sqrt{3} u_{d c 1}-2 u_{d c 2}\right) u_{r e f}}{4 u_{d c l} u_{d c 2}} \quad(\mathbf{3 7}, \mathbf{3 6}, \mathbf{5 2}, \mathbf{6 0}) \\
& \min \left(T_{36 \_c a l c}\right)=\frac{T_{s}\left(-u_{d c 1}+\sqrt{3} u_{d c 2}\right) u_{r e f}}{2 u_{d c l} u_{d c 2}} \quad(\mathbf{3 7}, \mathbf{3 6}, \mathbf{5 2}, \mathbf{3 9}) \\
& \min \left(T_{52-a l c}\right)=\frac{T_{s}\left(2 u_{d c 1}-\sqrt{3} u_{d c 2}\right) u_{r e f}}{4 u_{d c 1} u_{d c 2}} \quad\left(\mathbf{3 7}, \mathbf{3 6}, \mathbf{5 2}, \mathbf{6} \mathbf{0}_{\text {and }} \mathbf{5}\right) \\
& \min \left(T_{37_{-} c a l c}\right)=\frac{3 T_{s} u_{r e f}}{8 u_{d c 1}}-\frac{T_{s}\left(2 \sqrt{3} u_{d c 1}+u_{d c 2}\right) u_{r e f}}{8 u_{d c 1} u_{d c 2}} \quad\left(\mathbf{3 7}, \mathbf{3 6}, \mathbf{5 2}, \mathbf{3 9} \mathbf{a n d}_{\text {and }} \mathbf{4 8}\right)
\end{aligned}
$$

Because the application time of an active vector cannot be less than zero, the DC-link voltage ratio in the proposed method must satisfy the following relationship:

$$
\left\{\begin{array}{l}
\frac{1}{\sqrt{3}} \leq k \leq \sqrt{3} \quad(\mathbf{3 7}, \mathbf{3 6}, \mathbf{5 2}, \mathbf{6 0}) \operatorname{or}(\mathbf{3 7}, \mathbf{3 6}, \mathbf{5 2}, \mathbf{3 9}) \\
\frac{\sqrt{3}}{2} \leq k \leq \frac{2}{\sqrt{3}} \quad\left(\mathbf{3 7}, \mathbf{3 6}, \mathbf{5 2}, \mathbf{6 0}_{\text {and }} \mathbf{5}\right) \text { or }\left(37,36,52,3 \mathbf{9}_{\text {and }} 48\right)
\end{array}\right.
$$

(2) Modulation depth analysis

According to the application times of the zero vectors, the modulation depth of the linear modulation area can be obtained. Taking sector-1 as an example, the application times of the zero vectors are given by (15). Since the modulation depth can be calculated by the application times of the zero vectors, the maximal reference voltage in the $\boldsymbol{\alpha}-\boldsymbol{\beta}$ plane is equal to the smaller DC-link voltage, which is either $u_{d c 1}$ or $u_{d c 2}$.

$$
T_{0}= \begin{cases}T_{s}-\frac{T_{s} u_{\alpha}}{u_{d c 2}}+\frac{T_{s} u_{z 1}}{u_{d c 2}} & (\mathbf{3 7}, \mathbf{3 6}, \mathbf{5 2}, \mathbf{6 0}) \\ T_{s}-\frac{\sqrt{3} u_{\alpha} T_{s}}{2 u_{d c 1}}-\frac{u_{\beta} T_{s}}{2 u_{d c 1}} \frac{\sqrt{3} u_{z 1} T_{s}}{2 u_{d c 1}}+\frac{u_{z 2} T_{s}}{2 u_{d c 1}} \quad(\mathbf{3 7}, \mathbf{3 6}, \mathbf{5 2}, \mathbf{3 9}) \\ T_{s}-\frac{T_{s} u_{\alpha}}{u_{d c 2}}+\frac{T_{s} u_{z 1}}{u_{d c 2}} & \left(\mathbf{3 7}, \mathbf{3 6}, \mathbf{5 2}, \mathbf{6 0} \mathbf{0}_{\text {and }} \mathbf{5}\right) \\ T_{s}-\frac{\sqrt{3} u_{\alpha} T_{s}}{2 u_{d c 1}}-\frac{u_{\beta} T_{s}}{2 u_{d c 1}} \frac{\sqrt{3} u_{z 1} T_{s}}{2 u_{d c 1}}+\frac{u_{z 2} T_{s}}{2 u_{d c 1}} \quad\left(\mathbf{3 7}, \mathbf{3 6}, \mathbf{5 2}, \mathbf{3 9} \mathbf{a n d}_{\text {and }} \mathbf{4 8}\right)\end{cases}
$$

(3) Toggling points of two types medium vectors

If the application times of the medium vectors in sector- 1 are zero, the toggling points of the medium vectors can be calculated as:

$$
\left(\frac{\sqrt{3}}{2}-\mathrm{k}\right) \cos \theta+\frac{1}{2} \sin \theta=0
$$

Thus, when the reference voltage vector in the $\mathbf{z}_{\mathbf{1}}-\mathbf{z}_{\mathbf{2}}$ plane is zero, the togging point of the medium vectors in the sector- 1 is:

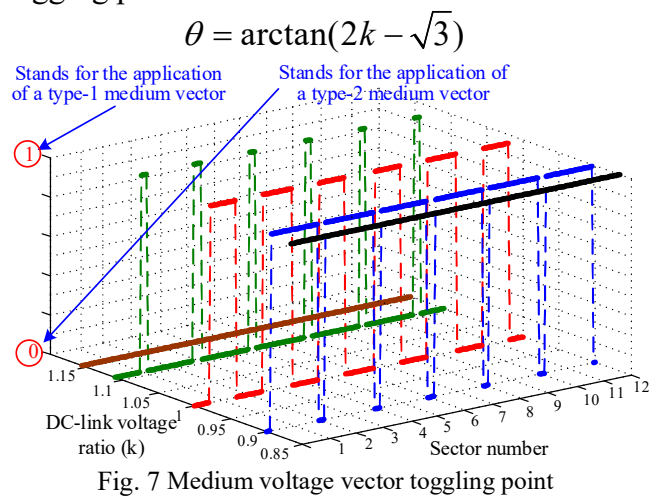




\section{IEEE POWER ELECTRONICS REGULAR PAPER/LETTER/CORRESPONDENCE}

It can be observed that the medium vector toggling point is determined only by the DC-link voltage ratio, and $u_{\text {ref }}$ does not affect the toggling point. The medium vector switching moments under different DC-link voltage ratios are obtained as shown in Fig. 7. 1 indicates the usage of type-1 medium vectors, and 0 indicates the usage of type- 2 medium vectors. The following conclusions can be obtained.

(1) The application times of type-2 medium vectors are shorter than those of type- 1 vectors if $\mathrm{k}<1$.

(2) The application times of type-1 vectors are shorter than those of type- 2 vectors if $\mathrm{k}>1$.

(3) When the DC-link voltage ratio is less than $\frac{\sqrt{3}}{2}$, type-1 medium vectors are always applied in sector-1.

(4) When the DC-link voltage ratio exceeds $\frac{2}{\sqrt{3}}$, type- 2 medium vectors are always applied in sector-1.

(5) The toggling point is at the center of the sector when the DC-link voltage is balanced. Therefore, the C6ФSVPWM12-A can be transformed to the modulation scheme proposed in [10]. E. Comparison of the proposed method with other SVPWM approaches under unbalanced voltages

Two typical six-phase SVPWM methods based on VSD are used for comparison purposes in this section. The first is the C6ФSVPWM approach proposed in [27] using four large voltage vectors, and the second is the C6ФSVPWM24 approach proposed in [10] using three large voltage vectors and one medium vector.

As an example, the DC-link voltage ratio is set to 0.9 . The borders of sector-1 and sector-2 under C6ФSVPWM and C6ФSVPWM24 are shown in Fig. 8(a), with the nonzero vector as the sector border. It can be observed that the sectors of conventional SVPWM are non-uniform under the unbalanced DC-link voltage, while the proposed method has fixed sectors. Therefore, the proposed method can reduce the calculation burden of the complicated sector classification.

If the voltage reference in $\mathbf{z}_{1}-\mathbf{z}_{\mathbf{2}}$ plane is neglected, the vectors application times of three methods in sector-1 are shown in Fig.8(b), It can be observed that the large vectors $\mathbf{4 5}$ and $\mathbf{5 2}$ in C6ФSVPWM have negative application times, and the application time of medium vector $\mathbf{6 0}$ in C6ФSVPWM24 becomes negative as the reference voltage phase increases. The proposed method avoids this negative application time by toggling the medium vector from $\mathbf{6 0}$ to 39. Therefore, the proposed method can easily choose the suitable vectors to track the reference voltage even though the DC-link voltage is unbalanced.

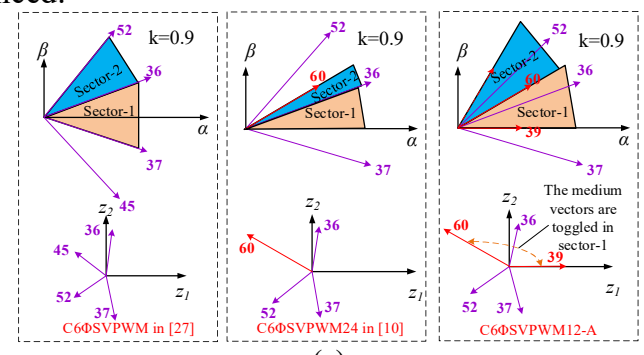

(a)
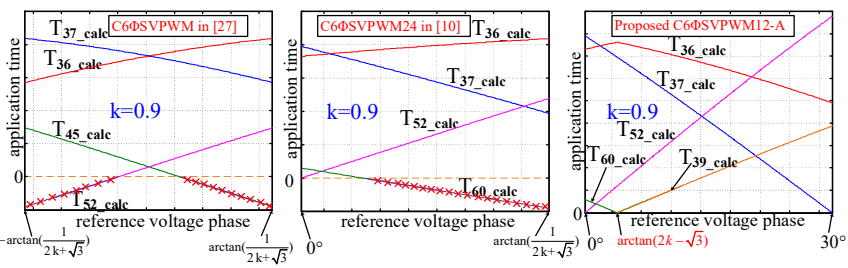

(b)

Fig. 8 Comparison of C6ФSVPWM, C6ФSVPWM24 and C6ФSVPWM12-A under $\mathrm{k}=0.9$. (a) Sector border and vector selection. (b) Calculated voltage vector application times.

\section{EXPERIMENT RESULTS}

The experimental platform is constructed based on two DClinks, as shown in Fig. 9(a). The dual three-phase PMSM is coupled with an asynchronous motor as the load. The dual three-phase driver is constructed by two single three-phase drives, which have the same power inverter topology as that in Fig. 1(c). The DC-link voltages are regulated by two dioderectifiers and transformers. The parameters of the dual threephase PMSM used in the experiment are given in Table IV. Field-oriented control (FOC), developed in [24] based on VSD, is adopted to control the speed of the dual three-phase PMSM (shown in Fig. 9(b)). The $\mathbf{z}_{\mathbf{1}}-\mathbf{z}_{\mathbf{2}}$ plane control scheme is based on synchronous frame current control using PI controllers to suppress the fifth and seventh current harmonics. The control parameters are shown in Table IV. The FOC and SVPWM algorithms are implemented by using a TMS320F28335 Texas Instruments digital signal processor, and the PWM pulse is generated by a EP2CQ208C8 field-programmable gate array (FPGA).

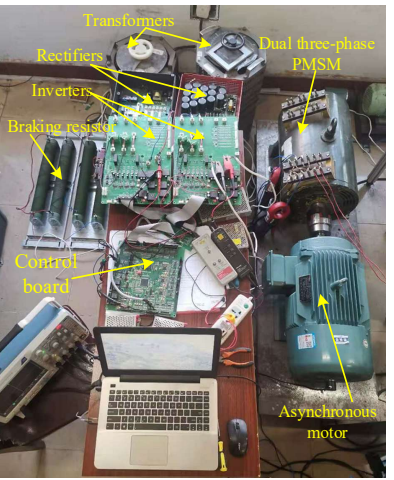

(a)

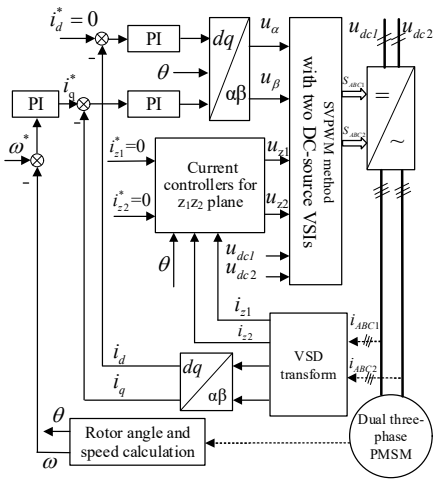

(b)
Fig.9 Experimental setup for dual three-phase PMSM driver. (a) Experimental platform. (b) Control method used in the experiment TABLE IV

Dual three-phase PMSM system parameters

\begin{tabular}{cc}
\multicolumn{2}{c}{ Dual three-phase PMSM system parameters } \\
\hline Parameter & Value \\
\hline Stator resistance $(\Omega)$ & 1.8856 \\
$d$-axis inductance $(\mathrm{H})$ & 0.0475 \\
$q$-axis inductance $(\mathrm{H})$ & 0.0783 \\
Rotor flux linkage $(\mathrm{Wb})$ & 0.942 \\
Pole pairs & 5 \\
Nominal DC-link voltage $(\mathrm{V})$ & 570 \\
PWM period (us) & 250 \\
Dead-band time (us) & 6 \\
Current loop proportional gain in $d q$ & 1.5 \\
Current loop integral gain in $d q$ & 0.001 \\
Current loop proportional gain in $z l z 2$ & 0.2 \\
Current loop integral gain in $z l z 2$ & 0.001 \\
Speed loop proportional gain & 6.4 \\
Speed loop integral gain & 0.001 \\
\hline
\end{tabular}




\section{IEEE POWER ELECTRONICS REGULAR PAPER/LETTER/CORRESPONDENCE}

\section{A. Comparative experiment for steady-state operation}

In this experiment, two conventional six-phase SVPWM methods, C6ФSVPWM and C6ФSVPWM24, are compared with the proposed method. Experimental results for the SVPWM strategy under $u_{d c 1}=495 \mathrm{~V}$ and $u_{d c 2}=570 \mathrm{~V}$ are presented in Fig. 10. The motor speed is controlled at 300rpm under the torque of $210 \mathrm{Nm}$. The steady-state stator line voltages and current waveforms under the conventional C6ФSVPWM and C6ФSVPWM24 methods and the proposed C6ФSVPWM12-A and C6ФSVPWM12-B techniques are shown in Fig. 10(a), (b), (c), and (d). It can be observed that the proposed C6ФSVPWM12-A and C6ФSVPWM12-B techniques lead to higher quality stator current waveform than the conventional C6ФSVPWM and C6 ФSVPWM24 methods. This is because the proposed SVPWM methods have the ability to control the current in the $\boldsymbol{\alpha}-\boldsymbol{\beta}$ and $\mathbf{z}_{1}-\mathbf{z}_{2}$ planes under an unbalanced DC-link voltage.

To further analyse the stator currents and voltages, the waveform data of $\mathrm{U}_{\mathrm{AB} 1}$ and $\mathrm{I}_{\mathrm{A} 1}$ are imported into MATLAB for fast Fourier transform (FFT) analysis. The FFT results of line voltage $\mathrm{U}_{\mathrm{AB}}$ under the four VSD based SVPWM approaches are shown in Fig. 10(e), (f), (g) and (h). As seen from the harmonic spectra, the conventional SVPWM methods contain more $6 \mathrm{k} \pm 1$ order harmonics, such as $5^{\text {th- }}, 7^{\text {th- }}, 11^{\text {th- }}$ and $13^{\text {th- }}$ order harmonics than the proposed methods, and this mainly results from the error voltage vectors selection under the unbalanced DC-link voltage. Consequently, the conventional SVPWM methods produce the most harmonic current under the unbalanced DC-link voltage as shown in Fig. 10(i) and (j), while the proposed C6ФSVPWM12-A and C6ФSVPWM12-B methods can suppress the stator current as shown in Fig. 10(k) and (m). The C6ФSVPWM12-B PWM technique has the lowest THD because the two medium voltage vectors are used in one PWM cycle, thereby producing a reduced ripple current.

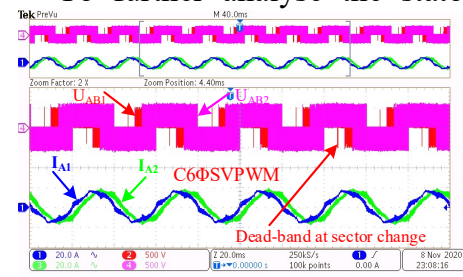

(a)

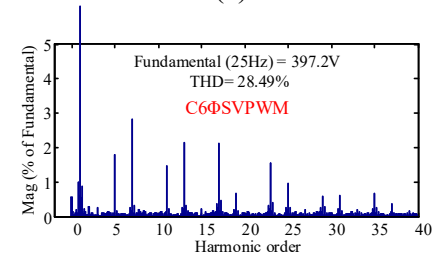

(e)

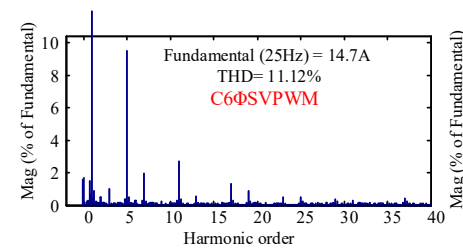

(i)

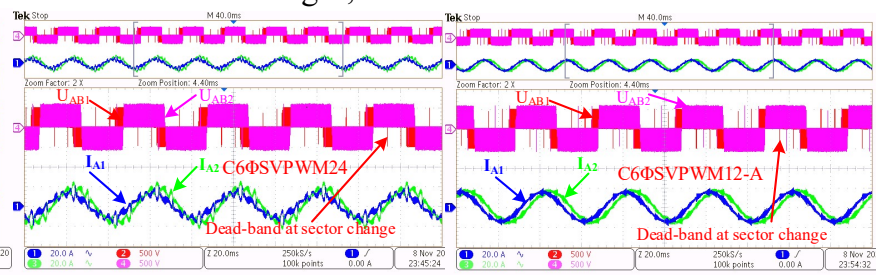

(b)

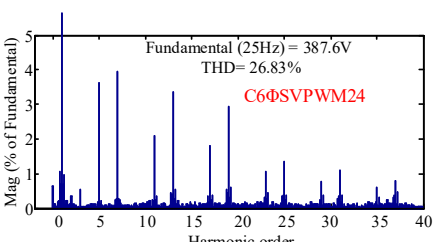

(f)

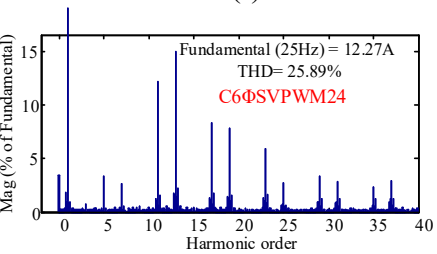

(j) (c)

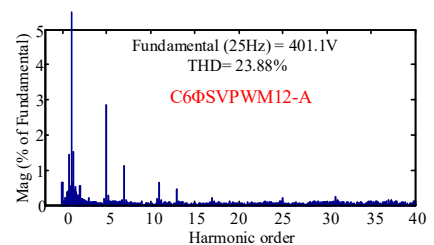

(g)

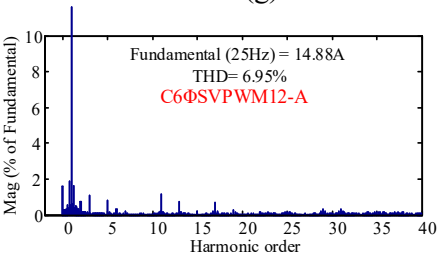

(k)

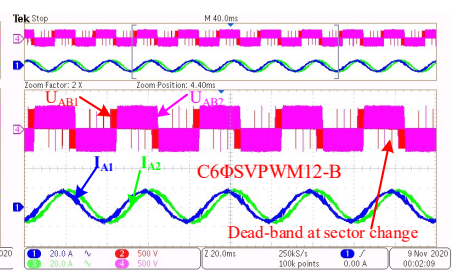

(d)

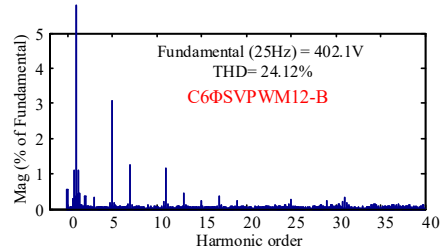

(h)

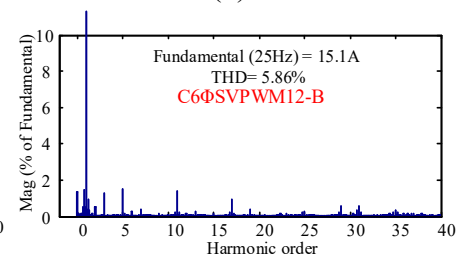

(m)

Fig.10 Experimental results for steady-state operation $\left(u_{d c 1}=495 \mathrm{~V}, u_{d c 2}=570 \mathrm{~V}, 25 \mathrm{~Hz}, 210 \mathrm{Nm}\right)$ using the C6ФSVPWM, C6ФSVPWM24, C6ФSVPWM12-A, and C6ФSVPWM12-B methods. (a), (b), (c), and (d) Stator voltages and currents under the four SVPWM methods. (e), (f), (g), and (h) FFT results for the stator voltages under the four SVPWM methods. (i), (j), (k), and (m) FFT results for the stator currents under the four SVPWM methods.

The four SVPWM methods (C6ФSVPWM, C6ФSVPWM24, C6ФSVPWM12-A, and C6ФSVPWM12-B) under different DC-link voltage ratios are compared in terms of their stator current total harmonic distortions (THDs). The THD results of stator current $\mathrm{I}_{\mathrm{A} 1}$ under different DC-link voltage ratios are presented in Fig. 11. The stator current THDs of the conventional C6ФSVPWM and C6ФSVPWM24 techniques increase rapidly as the DC-link voltage imbalance increases, and the THDs of C6ФSVPWM12-A and C6 less affected by DC-link voltage imbalances. These results confirm that the proposed SVPWM technique provides better performance than the conventional methods under unbalanced DC-link voltages. Since the proposed C6ФSVPWM12-A method is equivalent to C6ФSVPWM24 under a balance DC-

link voltage, the THD of the C6ФSVPWM12-A method is close to that of C6ФSVPWM24 when the DC-link voltages are the same. C6ФSVPWM12-B leads to a lower THD than that of C6ФSVPWM12-A. This is because two medium voltage vectors are used in one PWM cycle. The current THD of C6ФSVPWM24 under the $\mathrm{k}=495 / 570$ is obviously larger than that under $k=495 / 570$. The reason is that the current is unbalanced and the fundamental current (12.27 A) of phase A1 is less than those of the others (approximately 15A), as shown in Fig.10(i) (j) (k) (m). 


\section{IEEE POWER ELECTRONICS REGULAR PAPER/LETTER/CORRESPONDENCE}

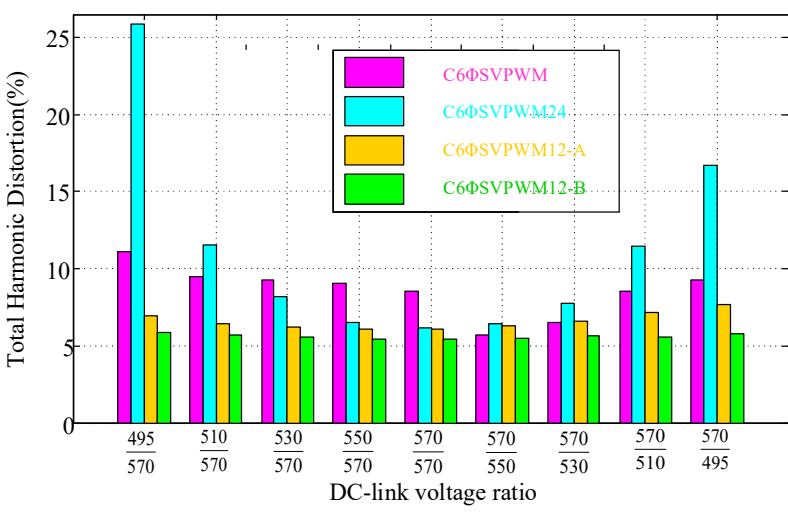

Fig.11 Stator current THDs for different SVPWM techniques at $25 \mathrm{~Hz}$ and 210 $\mathrm{Nm}$.

\section{B. Experiment with regard to dynamic operation}

The dynamic experiments are carried out by changing the motor speed. The rotational speed of the dual three-phase machine accelerates linearly from $100 \mathrm{rpm}$ to $300 \mathrm{rpm}$ and then decelerates to $100 \mathrm{rpm}$ with a constant load torque of $210 \mathrm{Nm}$. The dual three-phase PMSM electromagnetic torque, rotational speed and phase current for A1 and A2 under the proposed SVPWM methods are shown in Fig.12(a) and (b). It is evident that the phase current can remain balanced during the whole transient operation. It is shown that the proposed SVPWM methods can achieve good performances under a variable-speed operation. This paper focuses on solving the VSD-based SVPWM problem under unbalanced DC-link voltages, and it is necessary to verify the effectiveness of the proposed methods with dynamic changes in the DC-link voltage. Experimental results under manual $u_{\mathrm{dc} 1}$ changes are presented in Fig.12(c) and (d). $\mathrm{u}_{\mathrm{dc} 2}$ is set to $570 \mathrm{~V}$, and the motor speed and torque are set to the $300 \mathrm{rpm}$ and $210 \mathrm{Nm}$, respectively. It can be observed that the stator current can remain balanced in spite of DC-link voltage ratio fluctuations. The medium voltage vector toggling modulation approach proposed in this paper can control the output voltage effectively during the dynamic process.

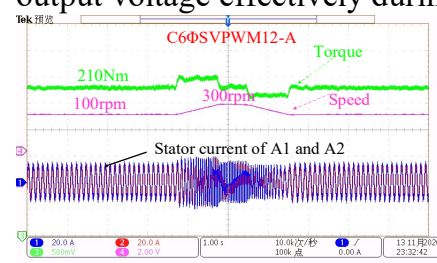

(a)

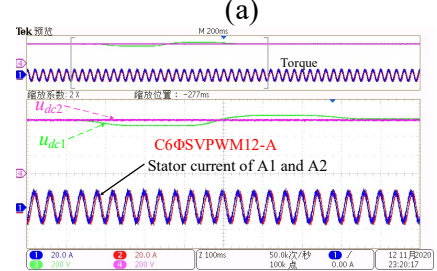

(c)

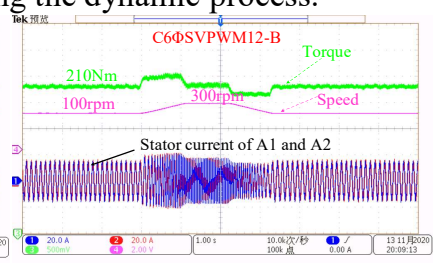

(b)

(d)

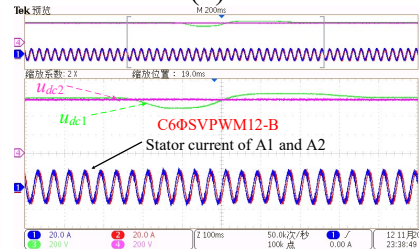

Fig. 12 Dynamic experimental results. (a) Speed transition under C6ФSVPWM12-A. (b) Speed transition under C6ФSVPWM12-B. (c) DC-link voltage transition under C6ФSVPWM12-A. (d) DC-link voltage transition under C6ФSVPWM12-B.

\section{CONCLUSION}

In this paper, an enhanced SVPWM technique suitable for imbalanced DC-link voltages based on VSD is investigated.
According to the characteristics of medium voltage vectors, two modulation strategies, C6 5 SVPWM12-A and C6ФSVPWM12-B, with medium voltage vector toggling are proposed. A detailed analysis of the proposed method in terms of the modulation depth, the range of the DC-link voltage ratio and the toggling point of the medium vector is presented. The proposed method can avoid complicated sector judgment algorithms under a non-uniform voltage vector distribution, and satisfy the voltage output requirements in the $\boldsymbol{\alpha}-\boldsymbol{\beta}$ and $\mathbf{z}_{1}-\mathbf{z}_{2}$ planes with a certain range of DC-link voltage ratio changes. The effectiveness of the proposed method is verified by comparative experiments on a prototype dual three-phase PMSM system. The obtained results show that the proposed methods provide lower stator current harmonic components than those of conventional six-phase SVPWM approaches under an imbalanced DC-link voltage, and the proposed C6ФSVPWM12-B method achieves better harmonic current performance than C6 5 SVPWM12-A. The dynamic experimental results confirm the viability of the proposed SVPWM method.

\section{APPENDIX}

\begin{tabular}{|c|c|}
\hline Applying time & value \\
\hline $\mathrm{T}_{1}$ & $\frac{T_{s}}{2 u_{c k}}\left(k u_{\alpha}-\sqrt{3} k u_{\beta}-k u_{z 1}-\sqrt{3} k u_{z 2}\right)$ \\
\hline $\mathrm{T}_{2}$ & $\left.\frac{T_{s}}{2 u_{d \mathrm{c}}}\left[-(\mathrm{k}-\sqrt{3}) u_{\alpha}+(\sqrt{3} k-1) u_{\beta}+(k+\sqrt{3}) u_{\mathrm{z} 1}+(\sqrt{3} k+1) u_{z 2}\right)\right]$ \\
\hline $\mathrm{T}_{3}$ & $\frac{T_{s}}{u_{d c 1}}\left(u_{\beta}-u_{z 2}\right)$ \\
\hline $\mathrm{T}_{4}$ & $\left.\frac{T_{s}}{2 u_{d c 1}}\left[(2 \mathrm{k}-\sqrt{3}) u_{\alpha}-u_{\beta}-(2 k+\sqrt{3}) u_{z 1}+u_{z 2}\right)\right]$ \\
\hline $\mathrm{T}_{5}$ & $\frac{T_{s}}{2 u_{d c 1}}\left(\sqrt{3} u_{\alpha}-u_{\beta}+\sqrt{3} u_{z 1}+u_{z 2}\right)$ \\
\hline $\mathrm{T}_{6}$ & $\left.\frac{T_{s}}{2 u_{d c 1}}\left[k u_{\alpha}-(\sqrt{3} k-2) u_{\beta}-k u_{z 1}-(2+\sqrt{3} \mathrm{k}) u_{z 2}\right)\right]$ \\
\hline $\mathrm{T}_{7}$ & $\left.\frac{T_{s}}{2 u_{d c 1}}\left[(\mathrm{k}-\sqrt{3}) u_{\alpha}+(\sqrt{3} k-1) u_{\beta}-(k+\sqrt{3}) u_{z 1}+(\sqrt{3} k+1) u_{z 2}\right)\right]$ \\
\hline $\mathrm{T}_{8}$ & $\frac{T_{s}}{u_{d x 1}}\left(k u_{\alpha}-k u_{z 11}\right)$ \\
\hline $\mathrm{T}_{9}$ & $\left.\frac{T_{s}}{2 u_{d c 1}}\left[k u_{\alpha}+(\sqrt{3} k-2) u_{\beta}-k u_{21}+(2+\sqrt{3} \mathrm{k}) u_{22}\right)\right]$ \\
\hline $\mathrm{T}_{10}$ & $\frac{T_{s}}{2 u_{\alpha 1}}\left(\sqrt{3} u_{\alpha}+u_{\beta}+\sqrt{3} u_{21}-u_{z 2}\right)$ \\
\hline $\mathrm{T}_{11}$ & $\left.\frac{T_{s}}{2 u_{d c 1}}\left[(2 \mathrm{k}-\sqrt{3}) u_{\alpha}+u_{\beta}-(2 k+\sqrt{3}) u_{z 1}-u_{z 2}\right)\right]$ \\
\hline $\mathrm{T}_{12}$ & $\frac{T_{s}}{2 u_{d c 1}}\left(k u_{\alpha}+\sqrt{3} k u_{\beta}-k u_{z 1}+\sqrt{3} k u_{z 2}\right)$ \\
\hline $\mathrm{T}_{13}$ & $\frac{T_{s}}{4 u_{c 1}}\left[\sqrt{3} u_{\alpha}+(1-2 \sqrt{3} k) u_{\beta}+\sqrt{3} u_{z 1}-(1+2 \sqrt{3} k) u_{z 2}\right]$ \\
\hline $\mathrm{T}_{14}$ & $\frac{T_{s}}{4 u_{d c 1}}\left[\sqrt{3} u_{\alpha}+(2 \sqrt{3} k-3) u_{\beta}+\sqrt{3} u_{z 1}+(3+2 \sqrt{3} k) u_{z 2}\right]$ \\
\hline $\mathrm{T}_{15}$ & $\frac{T_{s}}{4 u_{d c 1}}\left[(3 k-\sqrt{3}) u_{\alpha}+(3-\sqrt{3} k) u_{\beta}-(3 k+\sqrt{3}) u_{z 1}-(3+\sqrt{3} k) u_{z 2}\right]$ \\
\hline $\mathrm{T}_{16}$ & $\frac{T_{s}}{4 u_{d c 1}}\left[(\sqrt{3}-3 k) u_{\alpha}+(\sqrt{3} k+1) u_{\beta}+(3 k+\sqrt{3}) u_{21}+(\sqrt{3} k-1) u_{22}\right]$ \\
\hline $\mathrm{T}_{17}$ & $\frac{T_{s}}{4 u_{\alpha c 1}}\left[(2 k-\sqrt{3}) u_{\alpha}+3 u_{\beta}-(2 k+\sqrt{3}) u_{z 1}-3 u_{z 2}\right]$ \\
\hline $\mathrm{T}_{18}$ & $\frac{T_{s}}{4 u_{d c 1}}\left[(k+\sqrt{3}) u_{\alpha}+(\sqrt{3} k-3) u_{\beta}-(k-\sqrt{3}) u_{z 1}+(\sqrt{3} k+3) u_{z 2}\right]$ \\
\hline $\mathrm{T}_{19}$ & $\frac{T_{s}}{4 u_{d c 1}}\left[3 k u_{\alpha}+(2-\sqrt{3} k) u_{\beta}-3 k u_{z 1}-(\sqrt{3} k+2) u_{z 2}\right]$ \\
\hline $\mathrm{T}_{20}$ & $\frac{T_{s}}{4 u_{d c 1}}\left[(2 \sqrt{3}-3 k) u_{\alpha}+\sqrt{3} k u_{\beta}+(3 k+2 \sqrt{3}) k u_{21}+\sqrt{3} k u_{z 2}\right]$ \\
\hline $\mathrm{T}_{21}$ & $\frac{T_{s}}{4 u_{d x 1}}\left[(3 k-2 \sqrt{3}) u_{\alpha}+\sqrt{3} k u_{\beta}-(3 k+2 \sqrt{3}) k u_{z 1}+\sqrt{3} k u_{z 2}\right]$ \\
\hline $\mathrm{T}_{22}$ & $\frac{T_{s}}{4 u_{d x 1}}\left[-3 k u_{\alpha}+(2-\sqrt{3} k) u_{\beta}+3 k u_{z 1}-(\sqrt{3} k+2) u_{z 2}\right]$ \\
\hline $\mathrm{T}_{23}$ & $\frac{T_{s}}{4 u_{\alpha c 1}}\left[(k-2 \sqrt{3}) u_{\alpha}+\sqrt{3} k u_{\beta}-(k+2 \sqrt{3}) k u_{z 1}+\sqrt{3} k u_{s 2}\right]$ \\
\hline
\end{tabular}




\section{IEEE POWER ELECTRONICS REGULAR PAPER/LETTER/CORRESPONDENCE}

$\mathrm{T}_{24}$

$\mathrm{T}_{25}$

$\mathrm{T}_{26}$

$\mathrm{T}_{27}$

$\mathrm{T}_{28}$

$\mathrm{T}_{29}$

$\mathrm{T}_{30}$

$$
\begin{gathered}
\frac{T_{s}}{4 u_{d c 1}}\left[(2 \sqrt{3}-k) u_{\alpha}+\sqrt{3} k u_{\beta}+(k+2 \sqrt{3}) k u_{z 1}+\sqrt{3} k u_{z 2}\right] \\
\frac{T_{s}}{4 u_{c c 1}}\left[(3 k-\sqrt{3}) u_{\alpha}+(\sqrt{3} k+1) u_{\beta}-(3 k+\sqrt{3}) u_{z 1}+(\sqrt{3} k-1) u_{z 2}\right] \\
\frac{T_{s}}{4 u_{d c 1}}\left[(\sqrt{3}-3 k) u_{\alpha}+(3-\sqrt{3} k) u_{\beta}+(3 k+\sqrt{3}) u_{z 1}-(\sqrt{3} k+3) u_{z 2}\right] \\
\frac{T_{s}}{4 u_{d c 1}}\left[-\sqrt{3} u_{\alpha}+(2 \sqrt{3} k-3) u_{\beta}-\sqrt{3} u_{z 1}+(1+2 \sqrt{3} k) u_{z 2}\right] \\
\frac{T_{s}}{4 u_{d c 1}}\left[-\sqrt{3} u_{\alpha}+(1-2 \sqrt{3} k) u_{\beta}-\sqrt{3} u_{z 1}-(1+2 \sqrt{3} k) u_{z 2}\right] \\
\frac{T_{s}}{4 u_{d c 1}}\left[-(k+\sqrt{3}) u_{\alpha}+(\sqrt{3} k-3) u_{\beta}+(k-\sqrt{3}) u_{z 1}+(\sqrt{3} k+1) u_{z 2}\right] \\
\frac{T_{s}}{4 u_{d c 1}}\left[(\sqrt{3}-2 k) u_{\alpha}+3 u_{\beta}+(2 k+\sqrt{3}) u_{z 1}-3 u_{z 2}\right]
\end{gathered}
$$

\section{REFERENCES}

[1] P. Hollstegge, D. Keller, R. W. D. Doncker, "Dual Three-Phase Machine Modeling and Control Including Saturation, Rotor Position Dependency and Reduction of Low Current Harmonics," in Proc.7th International Electric Drives Production Conference (EDPC), Würzburg, Germany, Dec. 2017, pp. $1-9$.

[2] J. K. Pandit, M. V. Aware, R. V. Nemade, E. Levi, "Direct Torque Control Scheme for a Six-Phase Induction Motor with Reduced Torque Ripple," IEEE Trans. Power Electron., vol. 32, no. 9, pp. 7118-7129, Sept. 2017

[3] M. H. Holakooie, M. Ojaghi, A. Taheri, "Modified DTC of a Six-Phase Induction Motor with a Second-Order Sliding-Mode MRAS-Based Speed Estimator," IEEE Trans. Power Electron., 2019, vol. 34, no. 1, pp. 600-611, Jan. 2019.

[4] V. F. M. B. Melo, C. B. Jacobina, N. Rocha, "Fault tolerance performance of dual-inverter-based six-phase drive system under single-, two-, and threephase open-circuit fault operation," IET Power Electron., vol. 11, no. 1, pp. $212-220$, Feb. 2018.

[5] F. Barrero and M. J. Duran, "Recent Advances in the Design, Modeling, and Control of Multiphase Machines-Part I,". IEEE Trans. Ind. Electron., vol.63, no.1, pp. 449-458, Jan. 2016.

[6] Y. F. Zhao and T. A. Lipo, "Space Vector PWM Control of Dual Threephase Induction Machine Using Vector Space Decomposition," IEEE Trans. Ind. Appl., vol. 31, no. 5, pp. 1100-1109, Sept./Oct. 1995.

[7] Y. Ren, Z. Q. Zhu, J. E. Green, Y. Li, S. Zhu, Z. Li, "Improved Duty-RatioBased Direct Torque Control for Dual Three-Phase Permanent Magnet Synchronous Machine Drives," IEEE Trans. Ind. Appl., vol. 55, no. 6, pp. 5843-5853, Nov./Dec. 2019

[8] Y. Hu, Z. Q. Zhu, M. Odavic, "Comparison of Two-Individual Current Control and Vector Space Decomposition Control for Dual Three-Phase PMSM." IEEE Trans. Ind. Appl., vol. 53, no. 5, pp. 4483-4492, Sept./Oct. 2017.

[9] E. A. R. E. Ariff, O. Dordevic, M. Jones, "A Space Vector PWM Technique for a Three-Level Symmetrical Six-Phase Drive," IEEE Trans. Ind. Electron., vol. 64, no. 11, pp. 8396-8405, Nov. 2017.

[10] K. Marouani, L. Baghli, D. Hadiouche, A. Kheloui, A. Rezzoug, "A New PWM Strategy Based on a 24-Sector Vector Space Decomposition for a SixPhase VSI-Fed Dual Stator Induction Motor," IEEE Trans. Ind. Electron., vol. 55, no. 5, pp. 1910-1920, May 2008.

[11] S. Mo. Suhel and R. Maurya, "Modified SVPWM Techniques for SixPhase Asymmetrical Induction Motor Drives," in Proc. IEEE 1st International Conference on Energy, Systems and Information Processing (ICESIP), Chennai, India, Jul. 2019, pp. 1-6.

[12] K. Wang, X. You, C. Wang, M. Zhou, "An Equivalent Dual Three-phase SVPWM Realization of the Modified 24-Sector SVPWM Strategy for Asymmetrical Dual Stator Induction Machine," Proc. IEEE Energy Conversion Congress and Exposition (ECCE), Milwaukee, WI, USA, Sept. 2016, pp. 1-7.

[13] Shaikh Mohammed Suhel, Rakesh Maurya, "Realization of 24-Sector SVPWM With New Switching Pattern for Six-Phase Induction Motor Drive," IEEE Trans. Power Electron., vol. 34, no. 6, pp. 5079-5092, Jun. 2019.

[14] Z. Wang, X. Wang, X. Yang, C. Wen, Y. Gong, Y. Hu, "Mitigation of DC-Link Current Ripple for Dual Three-Phase Flux-Adjustable Hybrid PMAC Drives Using Collaborative Switching Strategy," IEEE Trans. Ind. Electron., vol. 67, no. 9, pp. 7202-7216, Sept. 2020.
[15] Z. Nie and N. Schofield, "Multi-phase VSI DC-link capacitor considerations," IET Electr. Power Appl., vol. 13, no. 11, pp. 1804-1811, Nov.2019.

[16] M. Vujacic, O. Dordevic, G. Grandi, "Evaluation of DC-Link Voltage Switching Ripple in Multiphase PWM Voltage Source Inverters," IEEE Trans. Power Electron., vol. 35, no. 4, pp. 3478-3490, Apr. 2020.

[17] H. S. Che, E. Levi, M. Jones, M. J. Duran, W. Hew, N. A. Rahim, "Operation of a Six-Phase Induction Machine Using Series-Connected Machine-Side Converters," IEEE Trans. Ind. Electron., vol. 61, no. 1, pp. 164-171, Jan. 2014.

[18] H. S. Che ,W. P. Hew ,N. A. Rahim, E. Levi, M. Jones, M. J. Duran, “A six-phase wind energy induction generator system with series-connected DC-links," in Proc. IEEE International Symposium on Power Electronics for Distributed Generation Systems (PEDG), Aalborg, Denmark, Jun. 2012, pp. 26-33.

[19] Oliver D., Thomas G., Peter H., "Feedforward Compensation of Torque Ripples in Dual Three-Phase PMSM Fed from Separate DC Links with Different Voltage Levels," IEEE Trans. Ind. Electron., to be published. DOI 10.1109/TIE.2020.3026293.

[20] S. Hu, Z. Liang, W. Zhang, X. He, "Research on the integration of hybrid energy storage system and dual three-phase PMSM drive in EV," IEEE Trans. Ind. Electron., vol. 65, no. 8, pp. 6602-6611, Aug. 2018.

[21] R. Bojoi, A. Tenconi, F. Profumo, and F. Farina, "Dual-source fed multiphase induction motor drive for fuel cell vehicles: Topology and control," in Proc. IEEE 36th Power Electron. Spec. Conf., Jun. 2005, pp. 2676-2683.

[22] S. Hu, M. Xiong, Z. Liang, X. He, "Torque Distributed Control Strategy for the Dual Three-Phase PMSM in Hybrid Energy Storage System Application," IEEE Trans. Ind. Electron., vol. 67, no. 4, pp. 2544-2552, April, 2020.

[23] Y. Hu, Zi-Qiang Zhu, K. Liu, "Current Control for Dual Three-Phase Permanent Magnet Synchronous Motors Accounting for Current Unbalance and Harmonics," IEEE Journal of Emerging and Selected Topics in Power Electronics, vol. 2, no. 2, pp. 272-284, Jan. 2014.

[24] H.Ye, W. Song, Z. Ruan, Y. Yan, "Current Control Methods for Dua Three-Phase Permanent Magnet Synchronous Motors Considering Machine Parameter Asymmetry," In Proc. 22nd International Conference on Electrical Machines and Systems (ICEMS), Harbin, China, Aug. 2019, pp. $1-6$

[25] Wang K., You X., Wang C., Zhou M.. An Equivalent Dual Three-phase SVPWM Realization of the Modified 24-Sector SVPWM Strategy for Asymmetrical Dual Stator Induction Machine. In Proc. IEEE Energy Conversion Congress and Exposition (ECCE), Sept. 2016, Milwaukee, WI, USA

[26] V. Oleschuk, R. Bojoi , V. Ermuratski, F. Profumo, "Synchronous Control of Six-Phase Traction Drive with Two DC Links," In Proc. Power Conversion Conference,Nagoya, Japan,Apr. 2007, pp. 942-948

[27] D. Hadiouche, L. Baghli, and A. Rezzoug, "Space-Vector PWM Techniques for Dual Three-Phase AC Machine: Analysis, Performance Evaluation, and DSP Implementation,” IEEE Trans. Ind. Appl., vol. 42, no. 4, pp. 1112-1122, JUL./AUG. 2006

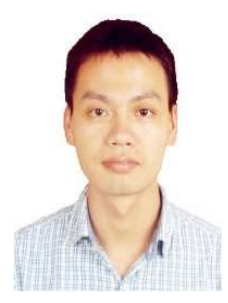

Wu Liao received the B.Sc. degree in automation in 2010 from Hunan University,Changsha, China,and the $\mathrm{Ph} . \mathrm{D}$. degree in electrical engineering from Hunan University, Changsha, in 2016.He was with CRRC Zhuzhou Institute Co., Ltd., Zhuzhou, China, as a converter software designer and researcher between 2016 and 2019 . He is currently with Hunan University as a Postdoctoral Researcher at the Department of Electrical Engineering. His research interests include wind power system, high power motor drives.

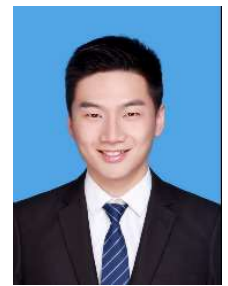

Mingcheng Lyu was born in Hunan, China, in 1990. He received Ph.D. degree College of Electrical and Information Engineering, Hunan University, Changsha, China, in 2020. Since 2020, he has been working toward the Post-doctoral research at the College of Electrical and Information Engineering, Hunan University, Changsha, China. His research interests include wind power generation technology, power quality control and applications of power electronics. 


\section{IEEE POWER ELECTRONICS REGULAR PAPER/LETTER/CORRESPONDENCE}
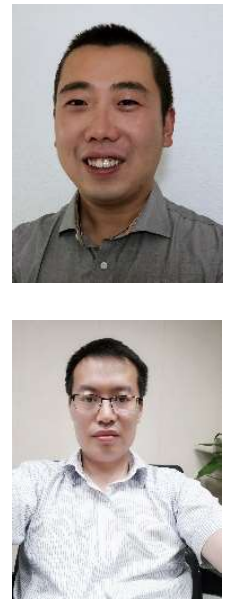

Sheng Huang received the M.S. and Ph.D. degree both in College of Electrical and Information Engineering, Hunan University, Changsha, China, in 2012 and 2016, respectively. He is currently a Postdoc with the Center for Electric Power and Energy, Department of Electrical Engineering, Technical University of Denmark. His research interests include renewable energy generation, modeling and integration study of wind power, control of energy storage system, and voltage control.

YuLiang Wen was born in LiLing, Hunan, China, in 1981. He received the B.S. and M.S. degrees in electrical engineering from Southwest Jiaotong University, Chengdu, China, in 2005 and 2008, respectively. He is currently working toward the Ph.D. degree in electrical engineering at the Central South University, ChangSha, China. Since 2018, he has been an Engineer in CRRC Zhuzhou Institute, Co., Ltd., Zhuzhou, China. His research interests include electrical traction system, AC motor drive system, pulse width modulation technique for traction converter, and the control technique of traction system for high-speed Maglev train.

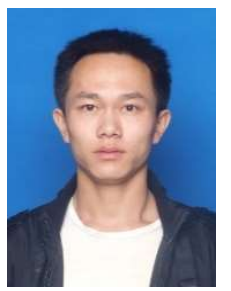

Mengdi Li received the M.S degrees in electrical engineering from Hunan University, Changsha, China, in 2017, respectively. He is currently working toward the $\mathrm{Ph} . \mathrm{D}$. degree at the College of Electrical and Information Engineering, Hunan University, Changsha, China, majoring in power electronics and electrical drive. His current research interests include advanced control of permanent magnet synchronous motor drive.

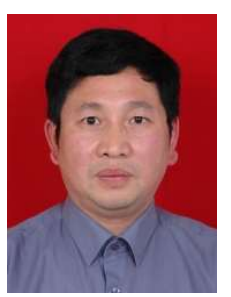

Shoudao Huang (SM'14) was born in Hunan, China, in 1962. He received the B.S. and Ph.D. degrees in electrical engineering from the College of Electrical and Information Engineering, Hunan University, Changsha, China, in 1983, and 2005, respectively. He is currently a Full Professor in the College of Electrical and Information Engineering, Hunan University, China. His research interests include wind energy conversion system, generator design and control, and electronic system and control. 